\title{
The male genitalia segments in fritillary butterflies: Comparative morphology with special reference to the "rectal plate" in Issoria (Lepidoptera: Nymphalidae)
}

\author{
THOMAS J. SIMONSEN* \\ Department of Entomology, Natural History Museum of Denmark (Zoology), University of Copenhagen, Universitetsparken 15, \\ DK-2100 Copenhagen, Denmark
}

Key words. Issoria, male genitalia, musculature, rectal plate, comparative morphology, phylogeny

\begin{abstract}
The male genitalia of the fritillary butterfly Issoria lathonia (L.) were examined and reconstructed based on sagittal and horizontal sections. Nine intrinsic muscles were identified consistent with previous results. The retractor of the anal tube probably operates the "rectal plate", a large, sclerotised, arched plate present ventral to the rectum and dorsal to the phallus in all Issoria s. str. species. The function of the rectal plate is still largely unknown, but it has presumably an important function during copulation. The retractor of the phallus inserts on the phallus, and also on a small, ventral sclerite in the anellus. The retractor of the vesica is smaller in I. lathonia than its counterpart in other Argynnini and originates more centrally inside the phallus. The tergal sclerite, common in most Argynnini, has no attaching muscle and its evolutionary origin remains unclear. The presence of an intrinsic muscle (i3) originating on the tegumen and inserting on the valve in Argynnini cannot be confirmed here. Though generally absent in butterflies, this muscle has been reported once in the North American Argynnis subgenus Speyeria.
\end{abstract}

\section{INTRODUCTION}

The male genitalia of Lepidoptera have been the subject of detailed studies over the past several decades and the morphology of male genitalia usually provides a basis for taxonomic and systematic works. The musculature, however, has been studied far less than the skeletal morphology. Snodgrass (1935) and Forbes (1939) published the first detailed accounts of the genitalic musculature, Birket-Smith (1974), Kristensen (1984) and Stekolnikov \& Kuznetzov (1986) addressed the Lepidoptera groundplan, and Kristensen (2003) provided a comprehensive overview of the groundplan and major evolutionary trends within the order. Kuznetzov \& Stekolnikov (2001a) published an extensive account (in Russian) of the genitalic musculature for most Lepidoptera families.

Skeletal morphology has time and again proved to be a very useful source of characters for phylogenetic analyses at various taxonomic levels. Within the tribe Argynnini (Nymphalidae: Heliconiinae) detailed examinations of the skeletal genitalia morphology formed the basis for the obtained phylogenies (Simonsen, 2005, in press). Other phylogenetic studies where detailed examinations of the skeletal genitalia morphology have been an important part include: Warren (1944, 1955), Warren et al. (1946), Dos Passos \& Grey (1945), Shirôzu \& Saigusa (1973, 1975) (all Argynnini), Emsley (1963), Penz (1999) (Heliconiini), Penz \& Peggie (2003) (Heliconiinae). These works span the taxonomic levels from subspecies and species (Warren 1944, Simonsen, 2005) to subfamily (Penz \& Peggie, 2003). The broad use of skeleton (genitalia) characters in phylogenetic works raise the need for detailed comparative studies of muscle morphology and insertion points, since such studies often are the only reliable methods to asses homology among highly variable structures and propose good character definitions.

Several studies have examined soft parts morphology of butterfly male genitalia: Stekolnikov et al. (2000) briefly addressed the Rhopaloceran groundplan, while Srivastava (1966) focused on Papilionidae; Kuznetzov \& Stekolnikov (1998) examined the Riodinidae and Lycaenidae. Within the Nymphalidae Kuznetzov \& Stekolnikov (2001b) examined Morphinae, Brassolinae and Satyrinae, and Ehrlich \& Davidson (1961) focused on Danaus (Danainae). The latter remains difficult to use, generally because of the complex genitalia of Danaus.

Forbes (1939) includes Argynnis (Speyeria) atlantis as the representative of butterflies in his pioneer work, and the Argynnini have since been the subject of some studies on the musculature of the male genitalia; Hannemann $(1954 a, b)$ gives a detailed account of the musculature of both the male and female genitalia of Argynnis paphia, Shirôzu \& Yamamoto (1959) give a detailed account of the male genitalia of Argynnis laodice japonica, whereas Arnold \& Fischer (1977) give a detailed examination of the abdominal musculature and copulation mechanisms in Speyeria (Argynnis s. 1. sensu Simonsen, 2004).

Building onto the previous studies mentioned above, here I re-examine the male genitalia of Issoria lathonia (Linnaeus, 1758) with special emphasis on the "rectal plate". This structure was first suggested by Warren (1955) to be a diagnostic character of "Issoria s. 1." and was later established as an important autapomorphy of

* Current address: Department of Biological Sciences, CW 405, Biological Sciences Centre, University of Alberta, Edmonton, Alberta, T6G 2E9 Canada; e-mail: thomas.simonsen@ualberta.ca 




Fig. 1. Paramedial sagittal reconstruction of the male genitalia. Abbreviations not referred to in the text are: Al: Anellus, AlS: Anellus Sclerite, Am: Ampulla, An: Anus, Co: Cornuti, DE: Ductus Ejaculatorius, Ju: Juxta, Ph: Phallus, R: Rectum, RP: Rectal Plate, RPa: Rectal Papillae, Sa: Saccus, Te: Tegumen, Un: Uncus, Ve: Vesica.

Issoria s. str. (Simonsen, in press). This study focuses on the intrinsic genitalia musculature and its origin and insertion points within the genitalia segments (A9-A10). Points of origin and insertion of extrinsic musculature outside the genitalia segments will not be considered. The method described by Birket-Smith (1965) for relaxing dry collection material was used for some of the preparations here. Therefore the efficiency of this method will be addressed briefly.

\section{MATERIAL AND METHODS}

Seven male I. lathonia were embedded in Monoject paraplast following the standard procedure. Three specimens were caught in the wild and fixed in Bouin's fluid immediately and subsequently stored in $70 \%$ ethanol. Due to the lack of additional freshly collected material I used four dried specimens from the collections of the Zoological Museum, University of Copenhagen (ZMUC). The four dried specimens were relaxed following Birket-Smith (1965) and subsequently stored in $70 \%$ ethanol. After embedding, the specimens were sectioned in 8

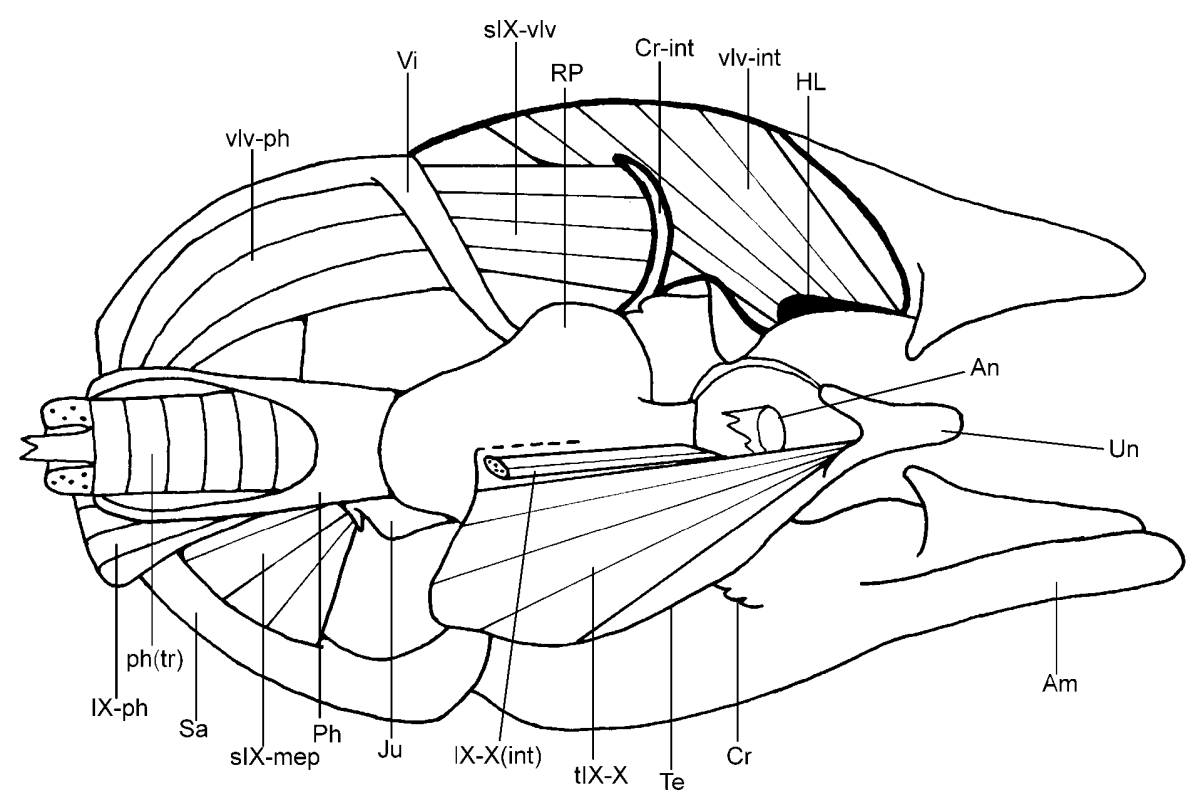

Fig. 2. Horizontal reconstruction of the skeleton and muscles of the male genitalia, dorsal view. Dorsal and left part of tegumen and dorsal part of the left valve removed. Abbreviations not previously referred to: Cr: Crista, Cr-int: Cristae interior, Vi: V inculum. 

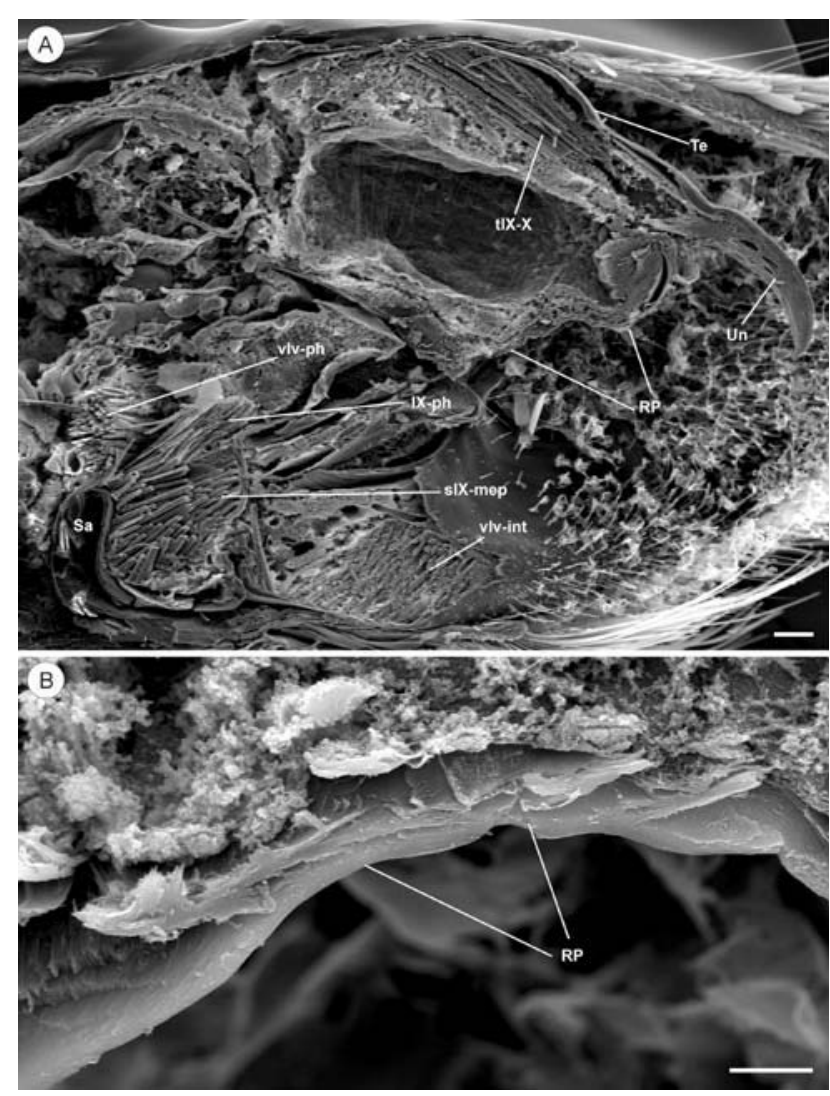

Fig. 3. SEM micrographs. A: Paramedial, sagittal cross section of the male genitalia showing tegumen, uncus, the rectal plate, saccus and the muscles; tIX-X, sIX-mep, IX-ph, vlv-int and vlv-ph. Phallus and juxta are removed. B: Detail of A, showing cross-section of the rectal plate. Scale bars: $A=0.1$ $\mathrm{mm}, \mathrm{B}=0.01 \mathrm{~mm}$.

$\mu \mathrm{m}$ sections using a Leica Jung Multicut 2045 microtome. Two freshly fixed and two of the relaxed specimens were sectioned in the sagittal plane, two relaxed specimens were sectioned in the horizontal plane and one freshly fixed specimen was sectioned in an approximation to the transverse plane. The latter was slightly tilted both from left to right and horizontally. One freshly fixed and the two relaxed specimens selected for sagittal sectioning were only sectioned up to the proximal medial line. The paraplast was subsequently resolved in benzol, and the halved genitalia were then freeze dried and coated with platinum for scanning electron microscopy (SEM).

The sections were stained with Weigert's haematoxylin, bluish erythrosine, phosphomolybdic acid and fast green. After staining the sections were embedded in entellan.

The nomenclature follows Kristensen (2003), but references to Forbes (1939), Shirôzu \& Yamamoto (1959) and Arnold \& Fischer (1977) are also given.

The genitalia of a freshly fixed single male Argynnis (Speyeria) cybele were halved in the sagittal plane using a razorblade. The two halves were subsequently cleaned in xylen and embedded in entellan. This was done to examine the presence of a specific dorso-ventral muscle reported in Argynnis (Speyeria) by Arnold \& Fischer (1977), but not reported by Forbes (1939) in $A$. (S.) atlantis, or in any other Rhopalocera (see below).

\section{OBSERVATIONS}

\section{General}

The tegumen is large, sclerotised and approximately as high as the vinculum. The tergal sclerite is small, but free.

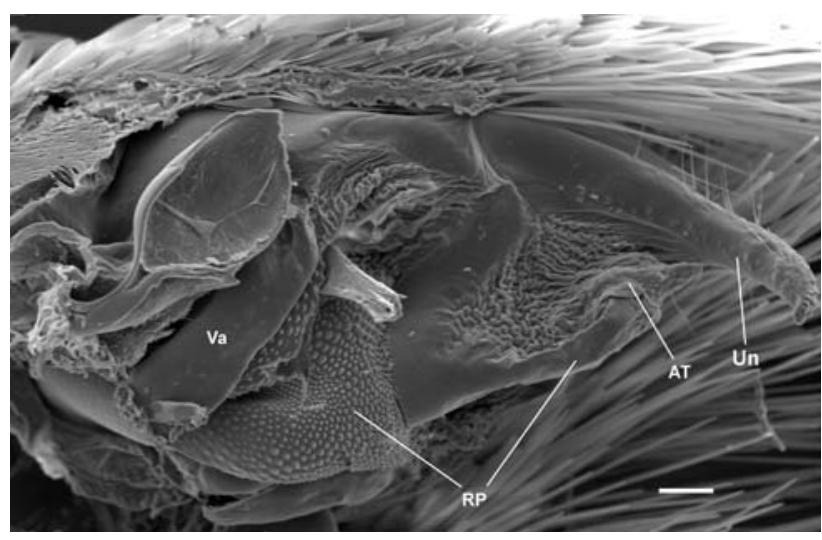

Fig. 4. SEM micrographs of tegumen, uncus and the rectal plate. A shows tegumen, vannus (Va), uncus, the rectal plate and the anal tube in latero-ventral view. The valves, vinculum and phallus are removed. Scale $b a r=0.1 \mathrm{~mm}$.

The uncus is short, simple and hollow (Figs 1-4). The ventro-anterior base is clearly thickened (Fig. 1). The vinculum is laterally narrow (Fig. 2), but ventro-anteriorly produced into a large, cup-shaped saccus (Figs 1-3, 7). The vanni are rectangular and narrow, fastening dorsally on the tegumen, and proceeding ventrally below the rectal plate (Figs 4, 5D). The juxta is large and bipartite (Figs 1, 5D). The phallus is short, but moderately stout, and the vesica is short with several sclerotised cornuti (Figs 1,7). The rectal plate is large and curved both longitudinally and transversely, reaching in length from the anterior end of the tegumen to the base of the uncus; it is smooth posteriorily, but otherwise it is densely granulated (Figs 1-6). The anal tube fastens dorsally at the base of uncus, and ventrally on the posterior margin of the rectal plate (Figs $1,4)$. The rectum is long, the posterior part is slender and undifferentiated running just dorsal of the rectal plate, the anterior part is widened with numerous rectal papillae (Fig. 1). The anellus lies as a collar or manica surrounding the phallus. It fastens dorsally on the anterior end of the rectal plate and ventrally on the juxta (Fig. 1). Centrally, it fastens on the phallus just anterior to the centre. Ventrally the anellus is sclerotised where it fastens to the phallus (Figs 1, 5F). The valve has an even ventral margin and a slightly sloping posterior margin. The terminal tip is pronounced with long setae and an inwards pointed dorsal tooth basally. The ampulla is large and sclerotised with microtrichia, but otherwise unmodified. The harp is elaborate and the external components comprise the harp fold and the crista, the former with a large, inward pointed tip, the latter is large, sclerotised and serrate, and dorsally in contact with the ampulla. In addition to the external structures mentioned, some internal structures deserve attention: a crista interior is present - a large sclerotised ridge originating on the inner surface of the crista and extending at a right angle into the valve lumen for more than half the lumen's width (Figs 2, 5D). A thickened, sclerotised, enforced, longitudinal list (here termed the harp list) is present internally on the ventral part of the harp. The posterior third of the valve is dorsally occupied by a large lumen, which is in contact with the outside of the animal via the harp groove/harp fold 


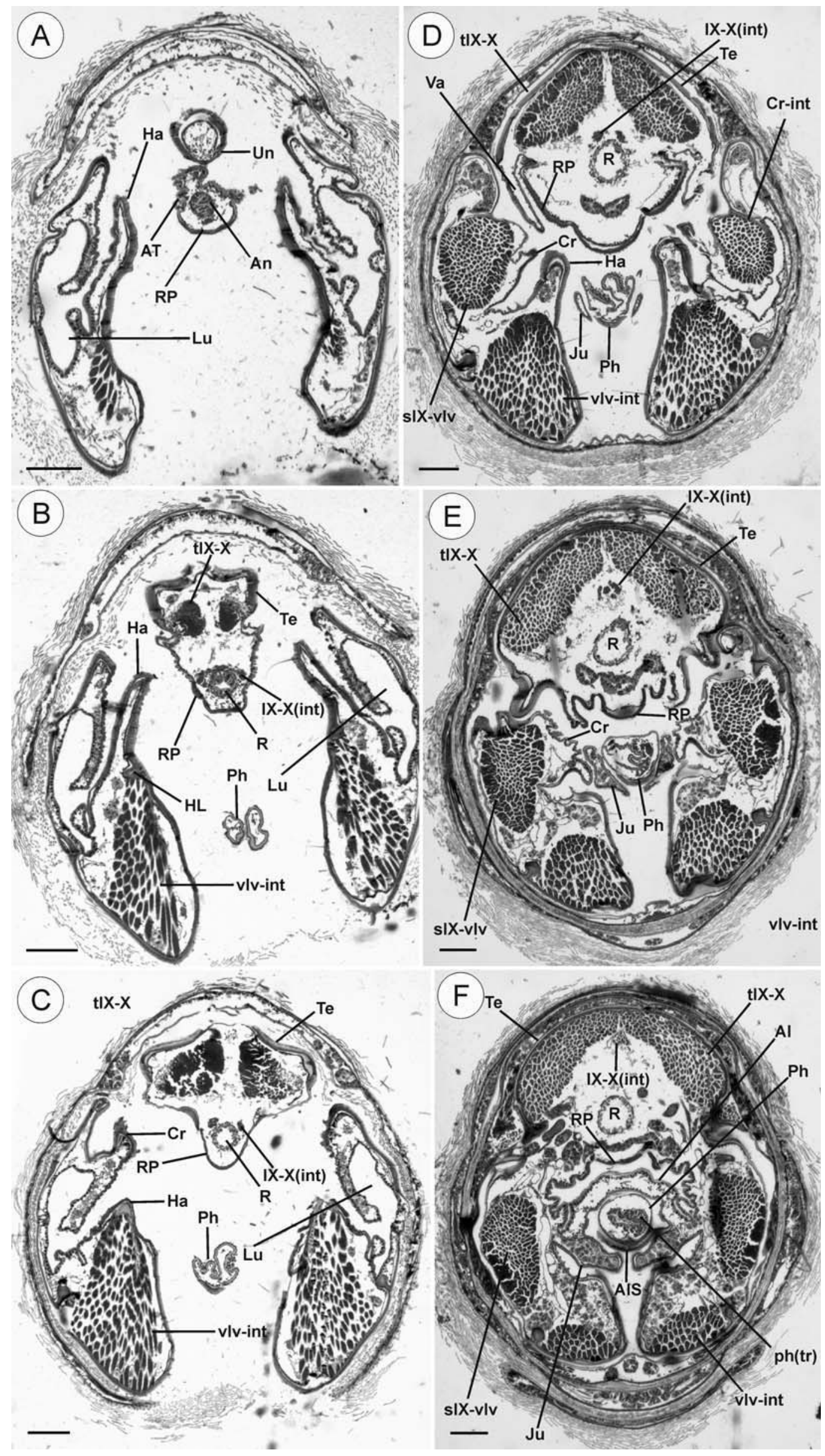




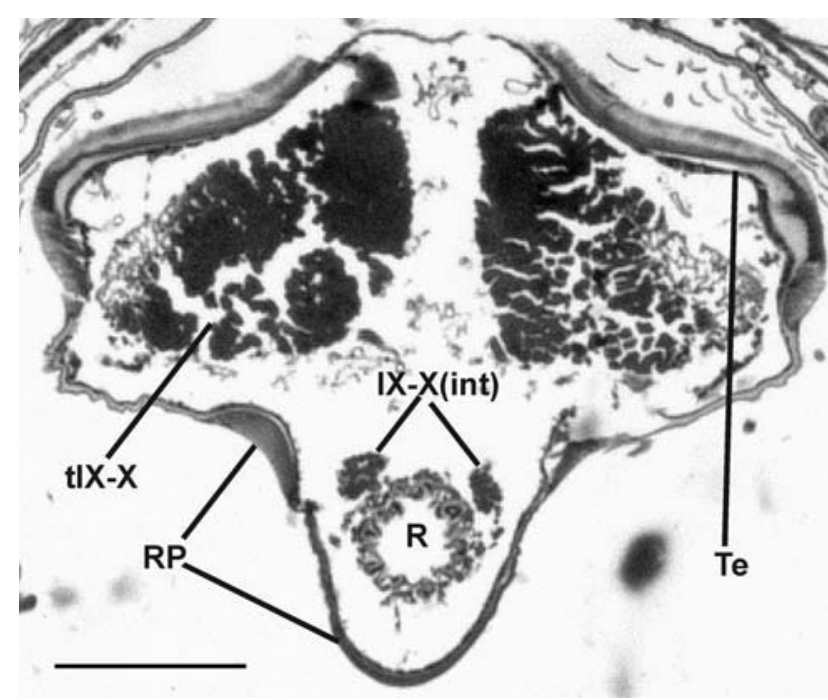

Fig. 6. Detail of Fig. 5C, showing the posterior parts of the rectal plate, rectum, tegumen, retractor of the anal tube and depressor of the uncus. Scale bar $0.2 \mathrm{~mm}$.

(Simonsen, in press). The lumen internal wall is covered by a layer of glandular cells (type 1 glandular tissue sensu Noirot \& Quennedey, 1991).

\section{Musculature}

Nine intrinsic genitalia muscles were identified. The designations in parentheses refer to the abbreviations in Kristensen (2003, in bold italics) used in the figures here and Shirôzu \& Yamamoto (1959, in italics), respectively.

Depressor of the uncus (tIX-X; i1) (Figs 1-3, 5B-F): Massive, originating latero-dorsally on the anterior part of tegumen, running inwardly and inserting on the reinforced ventral basis of the uncus.

Retractor of the anal tube (IX-X (int); i2) (Figs 1-2, $5 \mathrm{~B}-\mathrm{F})$ : A long and narrow strand of fibres. Originating dorso-anteriorly on the tegumen, just lateral to the central line, running slightly outwardly to insert on the partly sclerotised ventral basis of the anal tube and the posterior end of the rectal plate.

Extensor of the valve (sIX-vlv; i4) (Figs 1-2. 5D-F): A short, but massive muscle, originating on the posterior margin of the vinculum and inserting mainly on the crista interior but also on the dorsal valve margin anterior to the crista.

Flexor of the harp (vlv-int; i5) (Figs 1-2, 5A-F, 7): A massive muscle. Originating internally on the anterobasal part of the valve and inserting on the harp fold, mainly on the enforced harp list.

Protractor of the phallus (vlv-ph; i6) (Figs 1-3): A cone-shaped muscle, which is extremely large at its origin on the inner surface of the vinculum (it fastens on the ventral two-thirds of the vinculum), but much narrower at its insertion lateral on the phallobase.

Retractor of the phallus (IX-ph; i7) (Figs 1-3, 7): A large muscle, originating on the antero-dorsal part of the

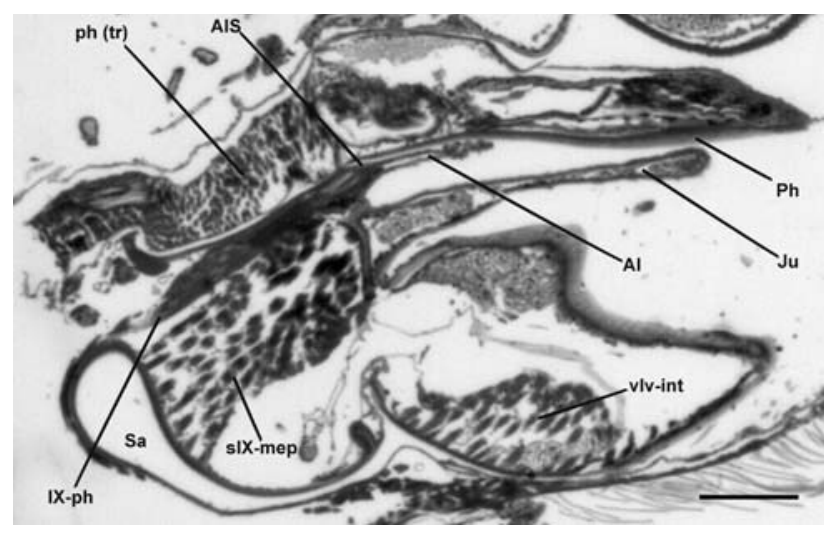

Fig. 7. Paramedial, sagittal cross section of the male genitalia, showing the phallus and its ventral surroundings. Note that the retractor of the phallus (IX-ph) does not only insert on the phallus it self, but also on the anellus sclerite and the ventral part of the anellus. Scale bar $0.2 \mathrm{~mm}$.

saccus and inserting ventrally on the phallus from the anterior end to (and on) the sclerotised ventral anellus.

Flexor of the valve or juxta-valve muscle (sIX-mep; i8) (Figs 1-3, 7): A massive muscle. Originating centrally on the posterior (inner) margin of the saccus. Inserting on the basis of the juxta.

Retractor of the vesica (ph(int); P1) (Fig. 1): A small muscle comprising only a few fibres. Originating centrally on the ventral inner surface of the sclerotised phallic tube. Inserting ventrally on the basis of the vesica.

Ejaculator muscle (ph(tr); P2) (Figs 1-2, 5F, 7): A prominent, telescopic muscle comprised of circular fibres surrounding the ductus ejaculatorius in the bulbus ejaculatorius.

Argynnis (Speyeria) cybele and the extensor of the tegumen (i3): In the whole-mount preparation of $A$. (S.) cybele examined here, there was no evidence of a dorsoventral intrinsic muscle originating dorso-anteriorly on the tegumen and inserting ventro-anteriorly on the valve.

\section{DISCUSSION}

\section{Musculature}

Most of the muscles described do not differ noticeably from those observed by Forbes (1939), Hannemann (1954a), Shirôzu \& Yamamoto (1959), Arnold \& Fischer (1977) and the Heliconiinae illustrated by Kuznetzov \& Stekolnikov (2001a). Nonetheless, some aspects deserve special attention.

The depressor of the uncus is apparently not as massive in I. lathonia as in the Argynnis (Speyeria) species examined by Forbes (1939) and Arnold \& Fischer (1977), or Argynnis paphia examined by Hannemann (1954a). In all these species this muscle is very broad at its origin, fastening dorso-ventrally on the entire anterior margin of the tegumen. In I. lathonia the depressor of the uncus originates only on the dorsal two-thirds of the anterior margin of the tegumen. In A. laodice according to the figures in

\footnotetext{
Fig. 5 (left). A series of cross-sections of I. lathonia male genitalia, with A being most posterior and F most basal. Scale bars $=0.2$
} $\mathrm{mm}$. 
Shirôzu \& Yamamoto (1959) and Heliconius according to the figures in Kuznetzov \& Stekolnikov (2001a), this muscle originates only on the dorsal half of the anterior margin of the tegumen. A possible explanation for this possibly lies in the size and shape of the uncus of the species in question. In A. paphia and most Argynnis (Speyeria) species the uncus is very large and curved or bent downward, in A. laodice and many Heliconius the uncus is considerably smaller and not as curved (close to straight in A. laodice). In I. lathonia, the uncus is intermediate in size. Hence, the muscular force required to operate the uncus is most certainly larger in A. paphia and Argynnis (Speyeria).

The retractor of the anal tube is probably relatively larger in I. lathonia than what has been reported for any other Argynnini. It was reported by Forbes (1939), Hannemann (1954a), Shirôzu \& Yamamoto (1959) and Arnold \& Fischer (1977) as a small muscle comprising only a few fibres. In contrast, in I. lathonia the retractor of the anal tube is a long, uniform, prominent bundle of fibres that originates dorso-anteriorly on the tegumen and inserts ventrally on the anal tube and the posterior end of the rectal plate. The muscle fibres insert both on the partly sclerotised portion of the tube close to the anus and on the sclerotised posterior tip of the rectal plate. Unlike the conditions in Argynnis (Speyeria) observed by Forbes (1939) and A. laodice observed by Shirôzu \& Yamamoto (1959), in I. lathonia this muscle comprises only a single bundle. This is the only observed muscle that can operate the rectal plate: a contraction will probably pull the posterior part of the rectal plate upwards, effectively closing the anus, and giving the phallus more room to operate. This possible extra function is probably the explanation for the relative larger size of this muscle in I. lathonia compared to other Argynnini species.

The absence of a dorso-ventral intrinsic muscle (i3) originating dorso-anteriorly on the tegumen and inserting ventro-anteriorly on the valve confirms observations by Forbes (1939), Hannemann (1954a), Shirôzu \& Yamamoto (1959) and Kuznetzov \& Stekolnikov (2001a), but is at variance with Arnold \& Fischer (1977) who reported such a muscle in Argynnis (Speyeria) (their male muscle 63 , extensor of the tegumen). Their finding is indeed surprising, and could not be confirmed here for $A$. (S.) cybele. Apparently, this muscle is also absent in Papilionidae (Srivastava, 1966), Lycaenidae and Riodinidae (Kuznetzov \& Stekolnikov, 1998), Morphinae and Brassolinae (Kuznetzov \& Stekolnikov, 2001b) and indeed all the Rhopalocera illustrated by Kuznetzov \& Stekolnikov (2001a). This muscle is probably also absent in Danaus; it does not seem to be among the muscles identified by Ehrlich \& Davidson (1961). The presence of a dorsoventral intrinsic muscle within the different butterfly groups therefore remains uncertain.

The extensor of the valve and the flexor of the harp of I. lathonia are both similar to what have been reported earlier for other Argynnini species. The former is short, but massive. It originates on the vinculum and inserts on the dorso-anterior valve margin and most notably on the crista interior. The latter muscle is equally massive. It originates on the ventro-anterior valve margin and inserts on the harp fold. It is very intriguing, however, that Kuznetzov \& Stekolnikov (2001a) do not illustrate this muscle in Heliconius charitonia (their Fig. 120b). This suggests that the absence/presence of this muscle could be of phylogenetic importance within the subfamily Heliconiinae. The functions of these two muscles are undoubtedly to operate the valves and different harp components during copulation. The weakly developed harp components in H. charitonia, compared to most Argynnini, may be the reason for the reduction of the harp flexor muscle in this species. Weather the reduction of the flexor of the harp is a generic character for Heliconius or perhaps a tribal character for Heliconiini is uncertain. $H$. charitonia belongs to the "pupal-mating" group within Heliconius, the members of this group have considerably more reduced harp components than more basal Heliconius species (C.M. Penz, pers. comm.) (a detailed study of the internal valve morphology of a broader taxon sampling of Argynnini and Heliconiini is underway and will be presented elsewhere, Simonsen, unpubl.).

Although the protractor of the phallus of I. lathonia is similar to that of the other examined Argynnini, the retractor of the phallus deserves some attention. As in the other Argynnini it originates from the distal part of the saccus, enwrapping the anterior end of this structure completely. It inserts ventrally on the phallus from the basal end to the anellus and most distally on a sclerite in the ventral anellus where the anellus inserts on the phallus. In Argynnis (Speyeria) (Forbes, 1939, Arnold \& Fischer, 1977) and A. paphia (Hannemann, 1954a) this muscle seems to insert on the base of the phallus exclusively, though it should be kept in mind that the anellus in these groups fastens rather basal on the phallus as well. In $A$. laodice (Shirôzu \& Yamamoto, 1959) this muscle inserts in a narrow band centrally on the phallus. I have found no other record from Rhopalocera indicating that it inserts on a sclerite in the anellus. Though the quality of laboratory equipment and microscopes should be taken into consideration, especially when considering older studies, it remains a possibility that this condition in I. lathonia is of genuine phylogenetic importance. Unfortunately, it is my experience that observing and hence homologising small sclerites in the anellus and other membranes as well is very difficult in $\mathrm{KOH}$ prepared specimens and the only truly reliable preparation method is the fairly timeconsuming one used here.

In I. lathonia the flexor of the valve is similar to that of other Argynnini species. The retractor of the vesica, however, differs to some extent from that observed in other Argynnini, where it is fairly large, originates at the basal end of the phallus and inserts on the vesica close to the gonopore. In both Argynnis (Speyeria) (Forbes, 1939, Arnold \& Fischer, 1977) and A. paphia (Hannemann, 1954 a) it originates on the ventro-basal ridge of the phallus, and in A. laodice (Shirôzu \& Yamamoto, 1959) it originates in the long phallic coecum. In I. lathonia this muscle is very small, comprising only a few fibres. It 
originates centrally on the ventral inner surface of the phallic tube and inserts ventrally on the vesica at some distance from the gonopore. If the size of this muscle is correlated to the eversibillity of the vesica, then the vesica of I. lathonia is far less eversible than the vesica of the earlier examined Argynnini. Comparing the present and previously published results it is reasonable to hypothesize that the size of the retractor of the vesica is correlated with the size and presence of a coecum or ventro-basal ridge on the phallus. The difference in the position of this muscle in different Argynnini could be of potential phylogenetic importance.

The ejaculator muscle of I. lathonia is larger than that of Argynnis (Speyeria) (Forbes, 1939, Arnold \& Fischer, 1977) and positioned more internally in the phallus than in both Argynnis (Speyeria) and A. laodice (Shirôzu \& Yamamoto, 1959). Hannemann (1954a) did not treat this muscle so its appearance in A. paphia cannot be considered here. Again, the position of this muscle may be of potential phylogenetic importance.

\section{Specialised structures}

The rectal plate

The function of the rectal plate remains uncertain. The retractor of the anal tube is apparently the only operator of the rectal plate. When this muscle retracts, the posterior part of the rectal plate is lifted, probably closing the anus. Additionally, the anterior part is probably lowered to some extent. These movements probably give the phallus more room to operate and could have a function during copulation. Examination of I. lathonia in copula is required to verify this possibility. Ideally, several $I$. lathonia couples should be colleted and killed (e.g. with liquid nitrogen) during copulation. They should then be prepared by the methods used here and sectioned in different planes (sagittal, horizontal and transverse) to determine the exact position of the rectal plate during copulation.

\section{The tergal sclerite}

The tergal sclerite (Warren, 1944, Simonsen, in press) is not here because no muscles attach to it. This is also the case in A. laodice (Shirôzu \& Yamamoto, 1959, plate 23, 2). Since neither Forbes (1939), Hannemann (1954) nor Arnold \& Fischer (1977) mention the tergal sclerite, it seems reasonable to assume that this is also the case in Argynnis (Speyeria) and A. paphia. Hence, the tergal sclerite in Argynnini does not seem to currently have any function, and it is not possible here to determine if it indeed is the rudiment of the gnathos as previously suggested (Warren, 1944). An examination of a broad sample of species from other Heliconiinae tribes may provide with useful information on this particular problem, since the presence and shape of the gnathos varies within the subfamily (Penz, 1999; Penz \& Peggie, 2003).

\section{The crista interior}

The internal ridge of the crista, here termed crista interior, is far more elaborate than what has been reported for other Rhopalocera. Indeed, a true crista interior has not hitherto been reported in Rhopalocera. This is surprising inasmuch as the external crista in A. paphia and Argynnis (Speyeria) is at least as stout and sclerotised as in I. lathonia. The reason for this difference may indeed lay in the methods and focus of previously published studies and not in the structures themselves. In this study the true nature of the crista interior could only be observed in the horizontal sections (and partly in the transverse sections) and not the sagittal sections. If earlier workers have relied only on sagittal sections, it is possible that they missed important details of this structure.

The internal harp list

Part of the insertion area for the flexor of the harp is a more prominent, enforced list or ridge than otherwise reported from other Rhopalocera. Since the list was only visible in cross sections, the reason for this is probably again at least partly the methods used in the different studies.

\section{The internal valve lumen}

The lumen of the valve of I. lathonia is similar to that found by Ockenfels et al. (1998) in the male valve of Argynnis paphia, including the glandular epithelium. This suggests that the male-female scent transfer system reported by those authors is widespread in Argynnini.

\section{Evaluation of Birket-Smith's relaxation method}

The relaxation of dried museum specimens in a phenolalcohol-glycerol solution for several days provided barely sufficient material for a study of the genitalia skeleton and musculature. The smaller muscles were generally damaged to some extent (especially the retractor of the anal tube). All finer structures (including most nonsclerotised membranes) were generally too damaged for detailed observations. Though the method proved useful for muscular studies it cannot replace well-fixed material. To be useful at all, this method probably also requires the specimens to have dried fairly quickly. If the drying conditions (e.g. in the field) have been bad or if the specimens have been relaxed later to spread them properly, the muscles and membranes probably rotted away and relaxation in a phenol-alcohol-glycerol solution will then be useless.

\section{CONCLUSIONS}

The musculature of I. lathonia is overall similar to that of other examined Argynnini. The depressor of the uncus is smaller than in Argynnis (Speyeria) and A. paphia, probably due to the smaller size of the uncus itself. The retractor of the anal tube is larger than in other Argynnini and comprises only a single bundle of fibres. The retractor of the phallus does not only insert on the phallus itself, but also on a small sclerite in the anellus ventral to the phallus. This arrangement is not seen elsewhere in Argynnini and may be of phylogenetic importance. The vesica retractor muscle is smaller than in other Argynnini and it originates more central inside the phallus that elsewhere in the group. This may also be of phylogenetic importance. The rectal plate is operated directly by the retractor of the anal tube, which also inserts on the partly 
sclerotised portion of the anal tube just posterior to the plate. Though the rectal plate probably has some function during copulation, this still remains uncertain and studies of I. lathonia in copula are required to verify this suggestion. The tergal sclerite has no muscles insertions and the origin of this small sclerite remains uncertain.

ACKNOWLEDGEMENTS. I wish to thank C.M. Penz (University of New Orleans, USA), S. Nylin (University of Stockholm, Sweden), and L.B. Vilhemsen (Zoology Dept., Natural History Museum, Copenhagen, Denmark) who read and commented upon the manuscript. N.P. Kristensen (Zoology Dept., Natural History Museum, Copenhagen, Denmark) provided invaluable comments and advice and introduced me to the techniques used. C. Häuser (Staatliches Museum für Naturkunde, Stuttgart, Germany) gave valuable advice on Lepidoptera genitalia. F. Vagilante (presently Museum für Naturkunde, Dresden, Germany) provided me with one of the fresh specimens of I. lathonia.

\section{REFERENCES}

ARNold R.A. \& Fischer R.L. 1977: Operational mechanisms of copulation and oviposition in Speyeria (Lepidoptera: Nymphalidae). Ann. Entomol. Soc. Am. 70: 455-468.

Birket-Smith S.J.R. 1965: A revision of the West African Eilemic moths, based on the male genitalia (Lep., Arctidae, Lithosinae; incl. gena. Crocosia, Eilema, Lithosia, Pelosia, Phryganopsis a. o.). Pap. Fac. Sci. Haile Selassie I Univ. (Ser. C, Zool.) 1: 1-161.

BiRKET-SMith S.J.R. 1974: Morphology of the male genitalia of Lepidoptera I. Ditrysia. Entomol. Scand. 5: 1-22.

Dos Passos C.F. \& Grey L.P. 1945: A genitalic survey of the Argynninae (Lepidoptera: Nymphalidae). Am. Mus. Nov. 1296: $1-29$.

EhrLich P.R. \& Davidson S.E. 1961: The internal anatomy of the Monarch butterfly (Danaus plexippus) L. (Lepidoptera: Nymphalidae). Microentomology. 24(3): 85-133.

EMSLEY M. 1963: A morphological study of imagine Heliconiinae (Lep. Nymphalidae) with a consideration of the evolutionary relationships within the group. Zoologica. 48: 85-130.

Forbes W.T.M. 1939: The muscles of the lepidopterous male genitalia. Ann. Entomol. Soc. Am. 32: 1-10

HanNemanN H.J. 1954a: Zur funktionellen Anatomie des männlichen Kopulationsapparates von Argynnis paphia (L.). Zool. Anz. 152: 266-274.

HANNEMANN H.J. 1954b: Zur Muskelfunktion der weiblichen Genitalsegmente von Argynnis paphia (L.) (Lep.). Zool. Anz. 153: $149-154$

KRISTENSEN N.P. 1984: The male genitalia of Agathiphaga (Lepidoptera: Agathiphagidae) and the lepidopteran ground plan. Entomol. Scand. 15: 151-178.

KRISTENSEN N.P. 2003: Skeleton and muscles: Adults. In Kristensen N.P. (ed.): Lepidoptera, Moths and Butterflies 2: Morphology, Physiology and Development. Handbook of Zoology Vol. IV, Part 36. Walter de Gruyter, Berlin-New York, pp. 45-145.

Kuznetzov V.I. \& Stekolnikov A.A. 1998: Evolution of the skeleton and muscles of male genitalia in the families Riodinidae and Lycaenidae (Lepidoptera). Entomol. Obozr. 77: 443-461 [in Russian; English translation in Entomol. Rev.].

Kuznetzov V.I. \& Stekolnikov A.A. 2001a: New Approaches to the System of Lepidoptera of World Fauna (on the Basis of the Functional Morphology of Abdomen). Proceedings of the Zoological Institute, Russian Academy of Sciences. Vol. 282. Nauka, St. Petersburg, 461 pp. [in Russian].
Kuznetzov V.I. \& Stekolnikov A.A. 2001b: Comparative morphology of the male genitalia in the subfamilies Morphinae and Brassolinae and the resurrection of the family Satyridae, status resurr. (Lepidoptera) in new limits. Entomol. Obozr. 80: 121-136 [in Russian; English translation in Entomol. Rev.].

NoIrot C. \& QueNNEDEY A. 1991: Glands, gland cells, glandular units: some comments on terminology and classification. Annls. Soc. Entomol. Fr. (N.S.) 27(2): 123-128.

Ockenfels P., Boppré M., Fischer O.W. \& Schultz S. 1998: Chemical Communication in the Silver-Washed Fritillary, Argynnis paphia (Lepidoptera, Nymphalidae). Poster from $15^{\text {th }}$ Annual Meeting of the International Society of Chemical Ecology.URL: http://www.chemecol.org/meetings/98/posters. html

Penz C.M. 1999: Higher level phylogeny for the passion-vine butterflies (Nymphalidae: Heliconinae) based on early stage and adult morphology. Zool. J. Linn. Soc. 127: 277-344.

Penz C.M. \& Peggie D. 2003: Phylogenetic relationships among Heliconinae genera based on morphology (Lepidoptera: Nymphalidae). Syst. Entomol. 28: 451-479.

Shirôzu T. \& SAIGUSA T. 1973: A generic classification of the genus Argynnis and its allied genera (Lepidoptera: Nymphalidae). Sieboldia 4: 99-104.

SHIRÔZU T. \& SAIGUSA T. 1975: The systematic position of Argynnis argyrospilata, Kotzsch (Lepidoptera: Nymphalidae). Sieboldia 6: 115-119.

Shirôzu T. \& Yамамото H. 1959: Morphology of the male genital organs of Argyronome laodice japonica Ménétriès (Lepidoptera: Nymphalidae). Sieboldia 1: 161-168.

SimONSEN T.J. 2005: Boloria phylogeny (Lepidoptera: Nymphalidae): tentatively reconstructed on the basis of male and female genitalic morphology. Syst. Entomol. 30: 653-665.

Simonsen T.J. (in press): Fritillary phylogeny, classification and larval hostplants: reconstructed mainly on the basis of male and female genitalic morphology (Lepidoptera: Nymphalidae: Argynnini). Biol. J. Linn. Soc.

SNODGRASS R.E. 1935: Principles of Insect Morphology. McGraw-Hill, New York, 667 pp. (1993 reprint, Cornell Univ., Ithaca).

SRivastava K.P. 1966: Studies on Lemon-Butterfly, Papilio demoleus L. (Lepidoptera). Part V. Skeleto-muscular system of abdomen. Zool. Anz. 177: 217-236.

Stekolnikov A.A. \& KuzNeTzov V.I. 1986: Origin and general trends in the evolution of the skeleton and musculature of the male genitalia in Lepidoptera. Entomol. Obozr. 65: 59-73 [in Russian; English translation Entomol. Rev. 65: 130-145].

Stekolnikov A.A., Ivanov V.A., Kuznetzov V.I. \& LuKhtanov V.A. 2000: Evolution of the chromosome mechanism, wing articulation, male genitalia and phylogeny of Butterflies (Lepidoptera: Hesperioidea, Papilionoidea). Entomol. Obozr. 79: 123-149 [in Russian; English translation in Entomol. Rev.].

WARREN B.C.S. 1944: Review of the classification of the Argynnidi: with a systematic revision of the genus Boloria (Lepidoptera: Nymphalidae). Trans. R. Entomol. Soc. Lond. 94: $1-101$.

WARREN B.C.S. 1955: A revision of the classification of the subfamily Argynninae (Lepidoptera: Nymphalidae). Part 2. Definition of the Asiatic genera. Trans. R. Entomol. Soc. Lond. 107: 381-391.

Warren B.C.S., Dos Passos C.F. \& Grey L.P. 1946: Supplementary notes on the classification of Argynninae (Lepidoptera: Nymphalidae). Proc. R. Entomol. Soc. Lond. 15: 71-73.

Received January 14, 2005; revised and accepted April 21, 2005 